\title{
† ÉDOUARD DE BONDELI
}

Le 5 octobre 1962 mourait, dans un accident de chemin de fer, Edouard de Bondeli.

C'est avec un profond regret que le Comité international de la Croix-Rouge a appris ce décès tragique du directeur financier et administratif de l'institution.

Issu d'une famille bernoise établie à Paris, Edouard de Bondeli était entré en 1942 au service du Comité international de la Croix-Rouge où il travailla d'abord au Service britannique de l'Agence centrale des prisonniers de guerre. Excellent administrateur, il fut nommé, en I950, sous-directeur chargé des services administratifs et financiers, et, tout récemment, directeur.

Doué d'une remarquable puissance de travail, il s'était voué à la tâche ardue de rechercher dans le monde les appuis matériels permettant à la Croix-Rouge de poursuivre son œuvre.

Ces quelques indications témoignent de l'utilité de la mission accomplie depuis de nombreuses années par Edouard de Bondeli au service de la Croix-Rouge, mission qu'il mena à bien en faisant preuve de grandes qualités d'énergie et d'intelligence. Sa disparition est douloureusement ressentie et le Comité international gardera de lui un souvenir fidèle et reconnaissant. 